\title{
Adamantinoma of Tibial Shaft
}

\author{
Joshi A, ${ }^{1}$ KC BR, ${ }^{1}$ Basnet SB, ${ }^{2}$ Panth R, ${ }^{3}$ Shrestha RL, ${ }^{4}$ Chand $\mathrm{P}$, ${ }^{1}$ Thapa BB ${ }^{1}$ \\ 'Department of Orthopedic, , Department of radiology, ${ }^{3}$ Department of pathology, ${ }^{4}$ Visiting orthopedic surgeon, Shree \\ Birendra Hospital, Chhauni, Kathmandu, Nepal.
}

\section{ABSTRACT}

Adamantinoma is an extremely rare primary bony neoplasm. Because of its malignant nature, accurate and early diagnosis is very important. On the other hand adamantinoma mimics many benign conditions, so it is doubly important to establish correct tissue diagnosis to avoid radical surgery with morbidities.

Because of its rarity, diagnosing adamantinoma still remains difficult, even if when it occurs in classical sites. We report a case of adamantinoma of tibial shaft diaphysis in a 23 year male. In this case, because of classic clinic-radiological features, we were suspecting adamantinoma from very beginning but final diagnosis was delayed for nine months.

Key Words: adamantinoma, diagnosis, rare tumor

\section{INTRODUCTION}

Adamantinoma is a rare bony tumor comprising only $0.1 \%-0.5 \%$ of a primary bone tumors. ${ }^{1}$ The tumor occurs almost exclusively in the long bones and tibia alone accounts for more than $80 \%$ of cases, diaphysis being the most affected with the age range from 12 to 57 years. Diagnosis is based upon clinical and radiological features and has to be confirmed by histopathology.
The histopathology has a multitude of variations not only among patients but also among different areas of same tumor making it further difficult to diagnose, requiring multiple biopsies. ${ }^{8,9}$ Although clinical, radiological and pathological features are well established in text books, it still remains one of the difficult tumors to diagnose.
Correspondence:

Dr. Amit Joshi

Department of Orthopaedics

Shree Birendra Army hospital

Chhauni, Kathmandu, Nepal.

Email: dr_amit_joshi@hotmail.com

Phone: $977-9841233850$ 


\section{CASE REPORT}

A 23 year male reported with chief complaints of pain and swelling anterior aspect of right leg for last nine months. Pain was continuous in nature, aggravated by activities and relieved by rest. There was a bony hard immobile swelling of about $4 \mathrm{~cm} \times 5 \mathrm{~cm}$ over the anterior aspect of right leg. The overlying skin was warmer but not adherent to underlying structures there were no sinuses, scar marks or venous engorgements. Plain $X-$ ray showed an expansile multicystic lesion at the diaphysis without any periosteal reactions (Figure $1 \mathrm{~A}$ ). With differential diagnosis of adamantinoma, fibrous dysplasia and osteomyelitis a core needle biopsy was performed. The histopathological impression of the biopsy was fibrous dysplasia. As the clinico-radiological diagnosis did not match the histopathological one, the patient was advised for regular follow up.

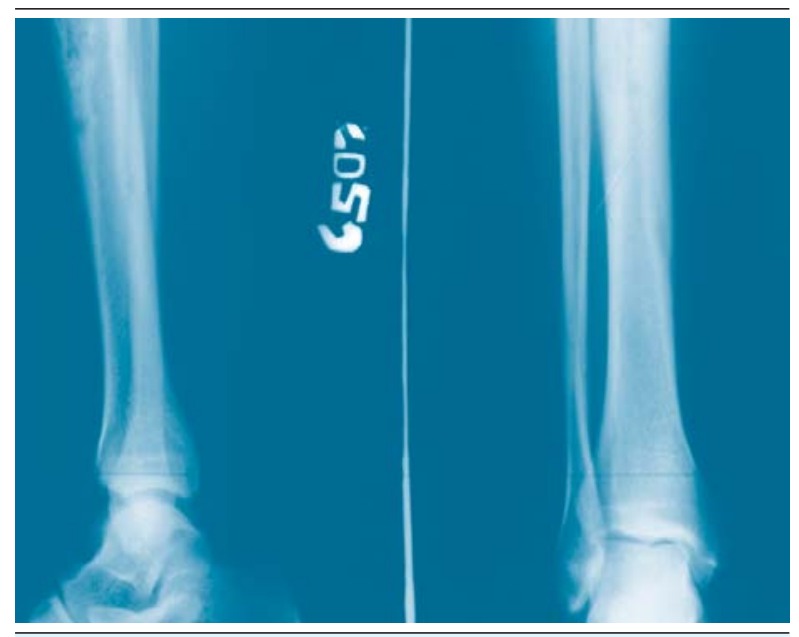

Figure 1. A. X-ray at the time of first presentation.

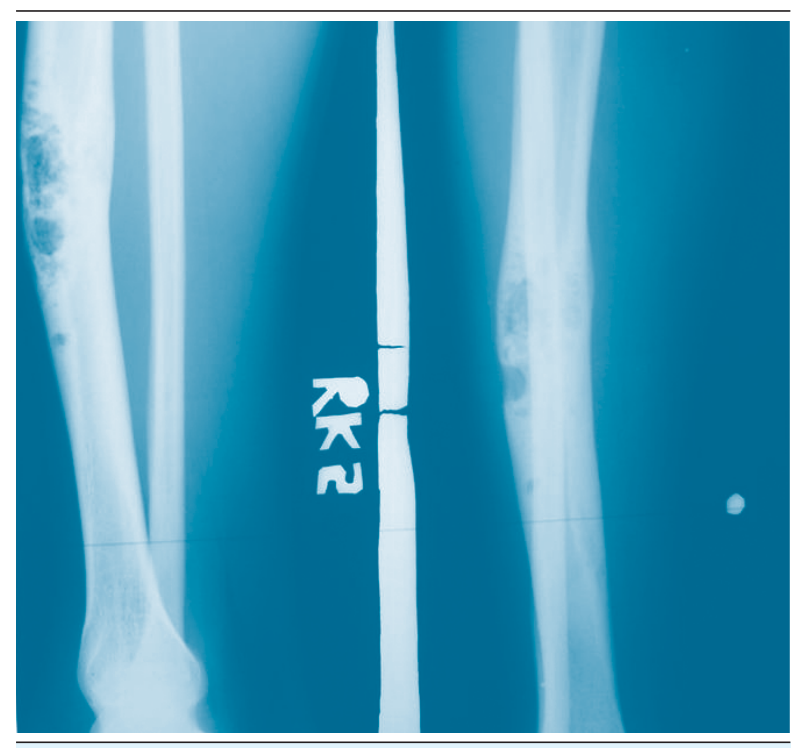

Figure 1. B. X-Ray at 6 month follow up

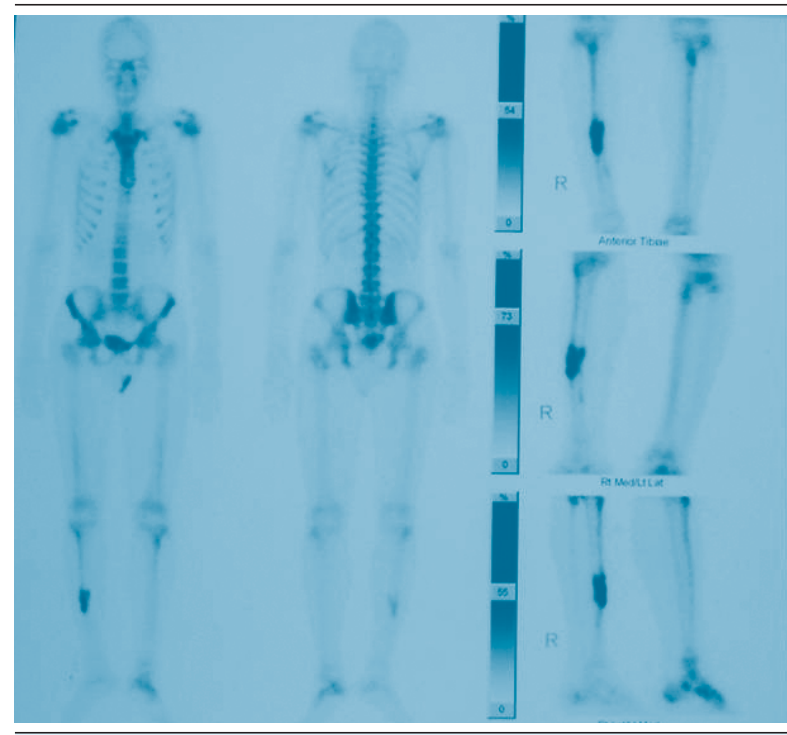

Figure 2. Bone scan

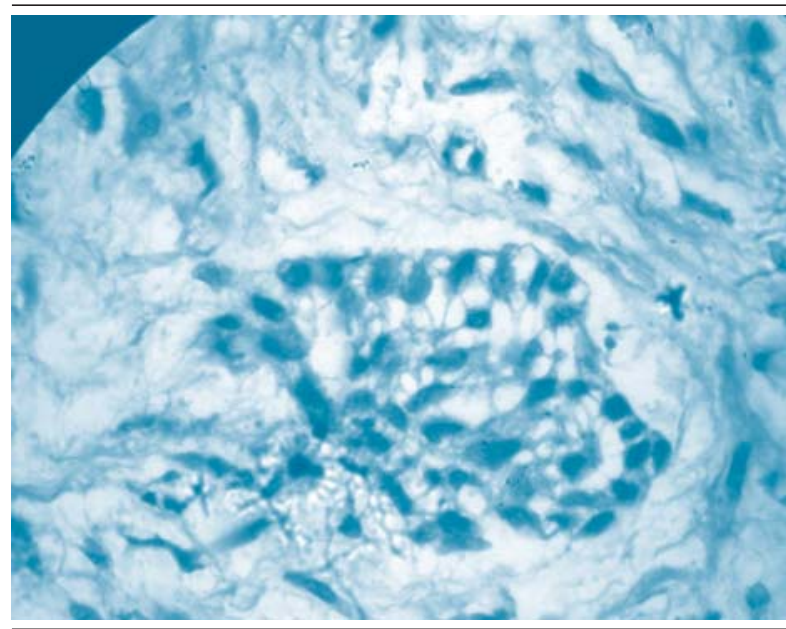

Figure 3. Histopathology: a cluster of cuboidal to columnar cells with peripheral palisading and central loosening

Over a period of six months, patient continued to have pain with slight increase in size of swelling. Comparison of series of X-rays (Figure $1 \mathrm{~A}$ and $\mathrm{B}$ ) showed progression of the lesion. New lesions had appeared and previous lesions had become larger and more defined. With this change in clinico-radiological features, a bone scan was planned. Bone scan showed hot spot at the affected side virtually ruling out the diagnosis of FD (Figure 2). In view of all features favoring adamantinoma, except the histopathological report, biopsy was repeated. Meticulous observation of the histology slides revealed very few clusters of epithelial cells in an osteofibrous stroma which was diagnostic of adamantinoma (Figure 3). After nine months of his first presentation to the hospital, a definitive diagnosis of adamantinoma of right tibial diaphysis was made. Patient had undergone wide resection of the tumor 
and put on llizarov ring fixator for bone transport to fill the gap created by wide resection.

\section{DISCUSSION}

Adamantinoma is riddled with many controversies, starting with its name and origin to behavior and its managements. ${ }^{10-16}$ Now its malignant nature has been established and $15 \%-20 \%$ of these tumors have been reported to metastasize to lung or regional lymph nodes. ${ }^{17}$ Its marginal resection has ended up with $90 \%$ recurrence rate. ${ }^{18}$ In view of its malignant nature and as it mimics many benign conditions which do not require any surgical intervention at all or may require minimal interventions, it is essential to establish a histopathological diagnosis before undertaking radical surgery with higher morbidities.

The patient was 23 year old (its peak incidence is in $2^{\text {nd }}$ decade), complained of pain (pain is the main symptom) with history of trauma (approximately $60 \%$ of patients with adamantinoma have a history of trauma). ${ }^{5}$ Gradual swelling with deformity of the affected limb, limping and increase in the pain with activity are common symptoms which were present there in our patient, but are not specific for adamantinoma.

Conventional radiograph can reveal enough clues to diagnose a lesion as adamantinoma and remain the gold standard of radiological diagnosis. The diaphyseal lesion, mainly of tibia which is eccentrically located, well circumscribed, slightly expansile, multilocular with intervening reactive sclerosis giving rise to "soap-bubble" appearance are characteristic features. Sometimes cortical thinning without periosteal reaction and bowing of tibia may be seen. ${ }^{19}$ All these features were present in X-ray of our patient which made us stick to the diagnosis of adamantinoma even though it was not supported by histopathology initially.

In contrast to similar benign lesions adamantinoma shows rather faster progression both clinically and radiologically. ${ }^{7}$ So, it is essential to have a close follow up. We followed up our patient in three months interval and in his second follow up we could see the radiological progression of the lesion which prompted us for bone scan and repeat biopsy.

The pathological diagnosis of adamantinoma is difficult not only because of its rarity but also because of ill developed histological features and marked variations in appearance of tumor. ${ }^{20}$ Though, baseloid, spindle cell, tubular and squamous pattern of adamantinoma have been described, a mixture of several pattern is observed in each case. ${ }^{20}$ Variation in appearance of adamantinoma is present not only among patients but also among different areas of tumor, requiring multiple biopsies to get a representative sample. ${ }^{9}$ In our case also we performed two biopsies to confirm adamantinoma histopathologically.

A critical analysis of this case revealed that a duly filled histopathological requisition form preferably by the treating surgeon and a preoperative discussion with pathologist would have decreased the time to arrive at final diagnosis.

A combined effort of clinicians, radiologists and pathologists is necessary to diagnose rare tumor like adamantinoma. If clinic radiological features are suggestive of a particular tumor but not supported by histopathology a close follow up and repeat biopsy should be undertaken, especially when suspecting a malignant tumor.

\section{REFERENCES}

1. Fechner R, Mills S. Tumors of the bones and joints. In: Atlas of Tumor Pathology. 3rd ed. Washington DC: LippincottRaven;1993.

2. Unni KK. Dahlin's Bone Tumors: general aspects and data on 11,087 cases. 5th ed. Philadelphia: Lippincott-Raven;1996.

3. Johnson LC. Congenital pseudoarthrosis, adamantinoma of long bone, and intracortical fibrous dysplasia of the tibia. J Bone Joint Surg Am. 1972;54:1355-9.

4. Moon NF. Adamantinoma of the appendicular skeleton. A statistical review of reported cases and the inclusion of ten new cases. Clin Orthop and Rele Res. 1966;43(1):89-213.
5. Baker PL, Dockerty MB, Coventry MB. Adamantinoma of the long bones. J Bone Joint Surg Br. 1954;36(A):704-20.

6. Bloem JL, Van der Heul RO, Schuttevaer HM, Kuipers D. Fibrous dysplasia vs adamantinoma of the tibia: differentiation based on discriminant analysis of clinical and plain film findings. Am J Roentgenology. 1991;156:1017-23.

7. Alguasil GA, Alonso A, Pettigrew NM. Osteofibrous dysplasia (ossyfying fibroma) of the tibia and fibula and adamantinoma. Am J Clin Pathol. 1984;82:470-4.

8. Huvos AG, Marcove RC. Adamantinoma of long bones. A clinicopathological study of fourteen cases with vascular origin suggested. J Bone Joint Surg. 1975;57(A):148-54. 
9. Filippou DK, Papadopoulos V, Kiparidou E, Demertzis NT. Adamantinoma of tibia: a case of late local recurrence along with lung metastases. J postgrad med. 2003;49(1):75-7.

10. Ishida T, Iijima T, Kikuchi F, Kitagawa T, Tanida T. A clinicopathological and immunohistochemical study of osteofibrous dysplasia, differentiated adamantinoma, and adamantinoma of long bones. Skel Radiol. 1992;21:493-502.

11. Ryrie BJ. Adamantinoma of the tibia: etiology and pathogenesis. Br Med J. 1932;2:1000-3.

12. Keeney GL, Unni KK, Beabout JW, Pritchard DJ. Adamantinoma of long bones. A clinicopathological study of 85 cases. Cancer. 1989;64:730-7.

13. Lederer H, Sinclair AJ. Malignant synovioma simulating "adamantinoma of the tibia". J Path Bact. 1954;67:163-9.

14. Naji AF, Murphy JA, Stasney RJ, Neville WE, Cherenka P. Socalled adamantinoma of long bones. J Bone Joint Surg. $1954 ; 46: 151-8$

15. Changus GW, Speed JS, Stewart FW. Malignant angioblastoma of bone. Cancer. 1957;10:540-59.
16. Elliot GB. Malignant angioblastoma of long bone. So-called “tibial adamantinoma”. J Bone Joint Surg Br. 1962;44:25-33.

17. Abid A, Qureshi MD, Susan S, Bruce AM, Steven G. Current trends in the management of adamantinoma of long bones, an international study. J Bone Joint Surg. 2000;82:11-22.

18. Gebhardt MC, Lord FC, Rosenberg AE, Mankin HJ. The treatment of adamantinoma of the tibia by wide resection and allograft bone transplantation. J Bone Joint Surg Am. 1987;69:1177-88.

19. Judmaier W, Peer S, Krejzi T, Dessl A, Kuhberger R. MR findings in tibial adamantinoma. A case report. Acta Radiol. 1998;39:27688.

20. Campanacci M, Giounti A, Bertoni F, Laus M, Gitelis S. Adamantinoma of the long bones: the experience at the Instituto Ortopedico Rizzoli. Am J Surg Pathol. 1981;5:533-42. 